\title{
Friendship acceptance on Facebook: men prefer cold calls from attractive women while women favour unattractive friends
}

\author{
Department of Psychology, \\ University of Bern, \\ Fabrikstrasse 8, 3012 Bern, Switzerland \\ and \\ w hoch $2 \mathrm{GmbH}$, \\ Kramgasse 5, 3011 Bern, Switzerland \\ Email: david.weibel@psy.unibe.ch \\ Email: wissmath@psy.unibe.ch \\ *Corresponding author
}

David Weibel ${ }^{*}$ and Bartholomäus Wissmath

\begin{abstract}
Our study broadens an experiment conducted by Wang et al. (2010). In their study, screenshots of fictitious Facebook profiles were presented to participants of a university class who were then asked whether they would be willing to accept a friendship. In contrast to the original study, we aimed to investigate actual behaviour of social media users instead of mere intentions. Therefore, we sent out actual friendship requests from male or female profile owners who were either attractive or unattractive. The requests were sent to a sample of 800 Facebook users. We could show that about $10 \%$ of these users responded to the cold calls. In line with Wang et al. (2010), male users accepted more invitations from attractive female profile owners. However, in contrast to Wang's findings, female users accepted invitations from unattractive profile owners rather than from attractive profile owners, regardless of the profile owners' gender.
\end{abstract}

Keywords: Facebook; internet dating; internet gender issues; social networking; attractiveness; cold calling.

Reference to this paper should be made as follows: Weibel, D. and Wissmath, B. (2018) 'Friendship acceptance on Facebook: men prefer cold calls from attractive women while women favour unattractive friends', Int. J. Web Based Communities, Vol. 14, No. 3, pp.249-256.

Biographical notes: David Weibel is a Lecturer in the Department of Psychology at the University of Bern. His main interests are human experiences and behaviour in mediated environments. He is focusing on topics such as the illusion of being in a virtual reality (presence), flow experiences, online games, social media, the influence of individual factors on presence, as well as identification with and embodiment in avatars.

Barthlomäus Wissmath's academic work focuses on human experiences and behaviour in the context of real, imagined, and virtual environments. $\mathrm{He}$ teaches statistics and research methods in various contexts. 


\section{Introduction}

Facebook is incredibly popular. Over one billion users are active monthly on the social networking site (Facebook, 2014). It is not surprising that Facebook has drawn the attention of researchers in various domains (cf. Wilson et al., 2012). A large body of recent research focused on identity presentation and impression formation (e.g., Back et al., 2010; Buffardi and Campbell, 2008; Carr et al., 2013). For example, Hall et al. (2014) found that observers of Facebook profiles accurately estimate profile owners' extraversion, agreeableness, and conscientiousness. In their study, participants gathered most of the information about identity through profile pictures. Various other studies also suggest that the first impression someone gives on Facebook strongly depends on their appearance on the profile picture (e.g., Scott, 2014). In line with these findings, Weibel et al. (2010) found that individuals establish a representation of their virtual interaction partner's character based on visible aspects. On Facebook as well as in the real world, we decide within a blink of an eye whether someone is attractive, likeable, intelligent, authoritarian, competent, or interesting (cf. Ambady and Skowronski, 2008). Various visual cues influence first impressions (King and Pate, 2002). Examples are clothes (Temple and Loewen, 1993), race (Hart and Morry, 1997), gender (Weibel et al., 2008), or perceived similarity (Lydon, Jamieson, and Zanna, 1988). Moreover, physical attractiveness influences impression formation in real life (e.g., Ambady and Rosenthal, 1992; Cash et al., 1977) as well as in virtual life (Weibel et al., 2010).

Within Facebook, Wang et al. (2010) examined the influence of attractiveness. The authors conducted an online survey where participants were exposed to a screenshot of a Facebook profile. The profile owner's face that appeared on the profile picture was either attractive or unattractive. These standardised stimuli had been previously evaluated in terms of attractiveness (Braun et al., 2001). In Wang's study, participants had to indicate on a seven-point Likert scale whether they would be willing to accept friendship invitations from the fictitious profile owners. The authors found that men, as well as women, are more willing to initiate friendships with opposite-gender profile owners that appear attractive on their profile pictures compared to profile owners who provide unattractive photos. This finding bears interesting implications: It points out that visual cues play an important role within online social interactions. Also, it is consistent with hyperpersonal model which proposes that within computer-mediated communications, impressions concerning partners are exaggerated based on displayed information (cf. Walther et al., 2001).

The study of Wang et al. (2010) provides information about how users think they would act in social media. However, they did not examine how users really behave: participants did not receive real Facebook invitations and instead, participated in an online survey and were not exposed to real profiles but to mere screenshots. Furthermore, participants had to indicate their willingness on a Likert scale, whereas in 'real' virtual life, friendship acceptance is a binary process (either an invitation is accepted or it is not accepted). The aim of the present study is therefore to extend the study of Wang et al. (2010) with a design that concerns actual behaviour in social media. In contrast to Wang et al. (2010), we created actual Facebook profiles of attractive and unattractive profile owners using the same profile pictures as Wang et al. (2010). Moreover, we sent out actual invitations to Facebook users and analysed whether the attractiveness of the profile owner influences the distribution of accepted invitations. Based on the results of Wang et al. (2010), we hypothesised that male as well as female users (participants) rather 
accept a friendship request from an unknown person (cold call) if an opposite-gender profile owner has an attractive profile picture compared to an unattractive profile picture.

\section{Method}

\subsection{Participants}

800 Facebook users were randomly chosen for our study. The selection procedure is described below in the procedure section. 400 of these users were male, 400 were female. Users with 100 to 1,000 friends were considered for our study. Reliable information about age could not be obtained for most participants. All participants were debriefed in a message after the experiment. They were informed about the design and purpose of the study. Also, they received individual and institutional contact information and were told that they could withdraw their data from the sample without any consequences.

\subsection{Design}

We applied a $2 \times 2 \times 2$ between-subjects univariate design. Factors were the attractiveness of the mock profile owner (attractive vs. unattractive), the profile owner's gender (male vs. female), and the actual user's gender (the participants: male vs. female). As a dependent variable, it was assessed whether the friendship request was accepted or not within three weeks.

\subsection{Stimulus material and procedure}

\subsubsection{Stimulus material: profile construction}

The profiles were similar to those used by Wang et al. (2010). Four profiles were constructed, two with a female profile picture and two with a male profile picture. For each, the picture was either attractive or unattractive (cf. Figure 1). The software-manipulated and standardised pictures were acquired from Braun et al. (2001). The authors had carefully tested the attractiveness of these photos in various previous experiments. In order to provide internal validity, other profile information was minimised. In line with the approach of Wang et al. (2010), a common male name was used for the two male profiles and a common female name was used for the two female profiles.

Figure 1 Pictures used for the profiles showing (a) an attractive female, (b) an unattractive female, (c) an attractive male and (d) an unattractive male person

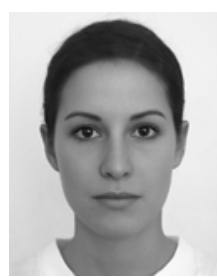

(a)

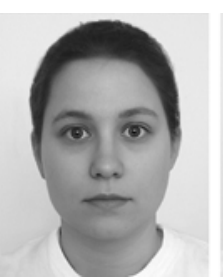

(b)

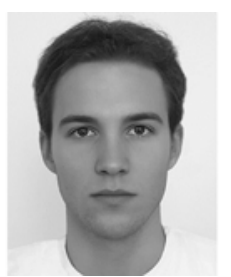

(c)

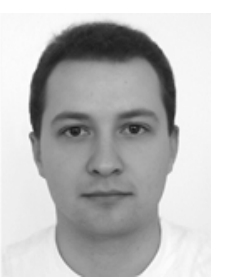

(d) 


\subsubsection{Selection of participants}

First, 400 pages of a telephone book were randomly selected. To select these pages, a random number generator was used. Then, the first distinctly female name, as well as the last distinctly male name, was chosen from the selected pages. In a next step, we searched for these names in Facebook. 800 users were found that met the criterion of having more than 99 and less than 1,000 friends.

\subsubsection{Distribution of friendship invitations}

We sent out friendship requests to these 800 Facebook users. Each of the four mock profiles was used to send requests to 100 female and 100 male Facebook users.

\section{Results}

We analysed the data using a log-linear analysis with the frequency of accepted friendship invitations as dependent variable.

\subsection{Overall results}

Overall, 70 out of 800 friendship invitations were accepted (9\%). Table 1 shows the amount of accepted invitations for each experimental condition.

Table 1 Distribution of accepted friendship invitations depending upon attractiveness, profile owner's gender, and user's gender

\begin{tabular}{|c|c|c|c|c|c|}
\hline & & \multicolumn{4}{|c|}{ Profile owner } \\
\hline & & \multicolumn{2}{|c|}{ Attractive owner } & \multicolumn{2}{|c|}{ Unattractive owner } \\
\hline & & Male owner & Female owner & Male owner & Female owner \\
\hline \multirow{2}{*}{$\begin{array}{l}\text { Facebook } \\
\text { user }\end{array}$} & Male user & 6 & 21 & 8 & 8 \\
\hline & Female user & 2 & 3 & 11 & 11 \\
\hline
\end{tabular}

\subsection{Test of hypothesis: requests from opposite-gender profile owners}

We could only partly confirm this hypothesis. In line with our expectations, male users accepted significantly more invitations from attractive female profile owners (21 accepted invitations) compared to invitations from unattractive female profile owners (8), $\chi^{2}(1, N=29)=5.83, p<.05$. For female users, however, the opposite effect occurred: invitations from attractive male profile owners were significantly less often accepted (2) than invitations from unattractive owners $(11), \chi^{2}(1, N=13)=6.23, p<.05$. The following interaction effect turned out to be highly significant, $\chi^{2}(1, N=42)$ $=11.78, p<.01$. Figure 2 illustrates this finding. 
Figure 2 Interaction between attractiveness and user's gender in terms of accepted invitations from opposite-gender profile owner

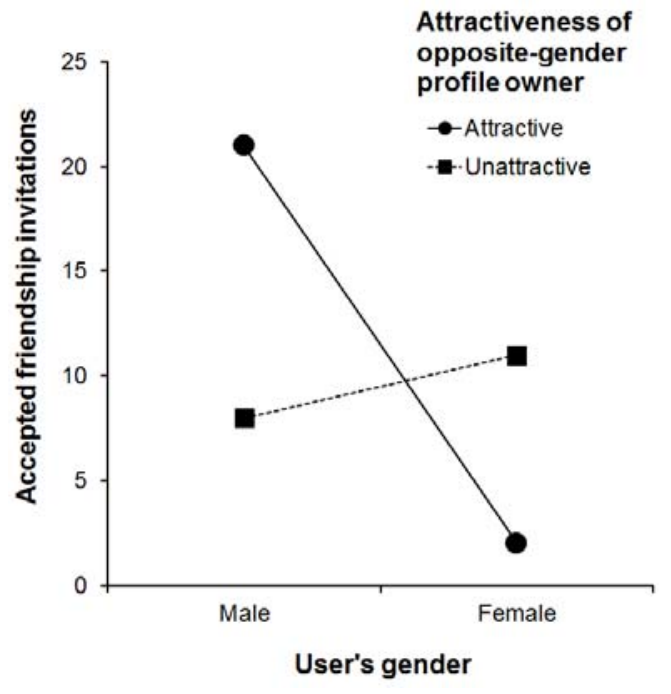

\subsection{Invitations from same-gender profile owners}

Female users accepted invitations from attractive profile owners significantly less often (3) compared to invitations from unattractive owners $(11), \chi^{2}(1, N=14)=4.57, p<.05$. Male users accepted six invitations from attractive and eight invitations from unattractive male profile owners; this difference was not significant, $\chi^{2}(1, N=14)=.29, p=.59$. The interaction between attractiveness and user's gender was not significant for same-gender requests, $\chi^{2}(1, N=28)=1.47, p=.21$. Figure 3 illustrates this finding.

Figure 3 Non-significant interaction between attractiveness and user's gender in terms of accepted invitations from same-gender profile owner

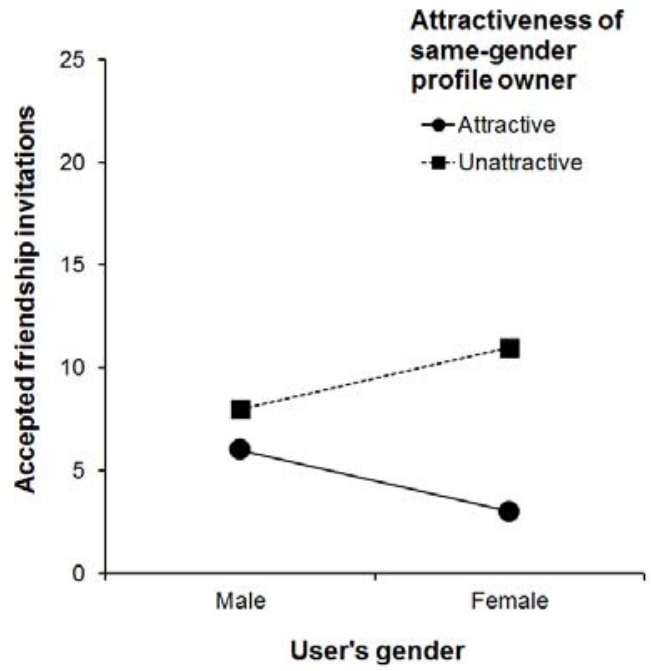




\section{Discussions}

In our study, about $10 \%$ of the friendship requests were accepted. These were requests by unknown persons. To our knowledge, this is the first study that could show that at least a certain amount of so-called called calls were accepted. The authors of the original study, Wang et al. (2010), point out the role of attractiveness in the context of virtual environments. Our findings which we claim to be more valid could partly replicate these findings. In line with Wang et al. (2010), attractiveness of female profile owner plays a crucial role for male users: male users accepted more requests from attractive female profile owners compared to requests from unattractive female profile owners. However, in contrast to Wang's findings, the effect was quite different for female users: they accepted invitations from unattractive profile owners rather than from attractive profile owners, regardless of gender. A possible explanation for this result could be that attractiveness is the primary desirability factor for men within the initial phase of a virtual relationship. This is plausible because:

1 individuals rely heavily on pictures in computer-mediated communication (Walther et al., 2001)

2 attraction is an easily available and apparent stimulus (Takeuchi, 2006).

The matching hypothesis proposes that individuals seek partners whose attraction equals their own (Walster et al., 1966). However, subsequent studies found that matching occurs in a later phase of dating, and that in the initial courtship formation, people try to attain the most attractive partners. For example, Taylor et al. (2011) showed that in an online dating setting, people frequently contacted others who were more attractive than themselves. Our results suggest that this, in fact, accounts for male behaviour in social networks such as Facebook. But why did attractiveness have an opposite effect on women? It might be because women do not use online environments as a courtship market to the same extent that men do (cf. Weiser, 2000; Chan et al., 2015).

This gender difference is also in line with White (1980) and Taylor et al. (2011) who both claim that the trend to attain attractive individuals in the initial contact phase is stronger for men than for women. This supports the findings of Muscanell and Guadagno (2012) who found that men use social networking sites to form new relationships, whereas women tend to use such sites to maintain relationships. According to Bleske-Rechek and Buss (2001), women perceive physical protection as an important factor for initiating an opposite-sex friendship. There is a growing body of research that suggests that women avoid attractive same-gender friends, since they are possible rivals (Bleske-Rechek and Lighthall, 2010). Other studies conclude that attractive friends make the women feel less attractive (Little and Mannion, 2005). This research is in line with our findings. However, we did not find any explanation for why women avoid the requests of attractive males. One possible ad hoc explanation could be that women feel that attractive profiles are more likely to be associated with an optimised, and therefore unauthentic, self-presentation. Given the female motivation to use social networks to maintain friendship (Muscanell and Guadagno, 2012), it seems plausible that women avoid optimised profiles and individuals where there is more of a potential or temptation for flirtation.

This study addresses long-standing questions about how attractiveness influences friendship choices in the context of social networks. Ambady and Rosenthal (1992) claim 
that the inclination to want to get to know someone or not strongly depends on visual cues. Similar to Wang et al.'s (2010) study, our results provide evidence that visual cues also play a crucial role in social interaction within online environments. Thus, as it is in the real world, attractiveness seems to be an essential factor for individuals to use in order to form impressions about others. This suggests that relationship development in computer-mediated communication is at least for men similar to face-to-face communication. Our study demonstrates that people establish a representation of their virtual interaction partner's character based upon visible aspects. In contrast to previous research, we could show that attractiveness not only influences the perceptions of others, but also has direct influence on how we choose our friends in social networks. To our knowledge, this current study is the first to show this, using actual online behaviour. Furthermore, our results provide evidence that first impressions matter in social networks for both women and men. Our study is relevant, since it is very likely that in the future, more human interactions will take place in cyberspace (Bainbridge, 2007). Therefore, the importance of choosing the right profile picture within social networking sites becomes obvious. Unlike our offline appearance, the shape of our online appearance is much more malleable and can be rapidly adapted in more subtle ways. Moreover, we believe that this study also raises interesting questions concerning the role of attractiveness in offline friendships.

Ecological validity is provided in our study. However, it should be noted that, due to standardisation, our design did not include important characteristics that Facebook profiles typically provide (e.g., interests, photos other than the actual profile pictures, work and education information). Future studies could consider these factors as well. Furthermore, it may be that participants from different cultures took part in our experiment. However, we did not assess this information. Because this factor may have an influence on whether someone accepts or rejects a friendship request on Facebook, the cultural background could be included in future studies.

\section{References}

Ambady, N. and Rosenthal, R. (1992) 'Thin slices of behavior as predictors of interpersonal consequences: a meta-analysis', Psychological Bulletin, Vol. 2, No. 2, pp.256-274.

Ambady, N. and Skowronski, J.J. (2008) First Impressions, Guilford, New York.

Back, M.D., Stopfer, J.M., Vazire, S., Gaddis, S., Schmukle, S.C., Egloff, B. and Gosling, S.D. (2010) 'Facebook profiles reflect actual personality, not self-idealization', Psychological Science, Vol. 21, No. 3, pp.372-374.

Bainbridge, W.S. (2007) 'The scientific research potential of virtual worlds', Science, Vol. 317, No. 5837, pp.472-476.

Bleske-Rechek, A.L. and Buss, D.M. (2001) 'Opposite-sex friendship: sex differences and similarities in initiation, selection, and dissolution', Personality and Social Psychology Bulletin, Vol. 27, No. 10, pp.1310-1323.

Bleske-Rechek, A.L. and Lighthall, M. (2010) 'Attractiveness and rivalry in women's friendships with women', Human Nature, Vol. 21, No. 1, pp.82-97.

Braun, C., Gruendl, M., Marberger, C. and Scherber, C. (2001) Beautycheck - Schönheit ist messbar (Beutycheck - Beauty can be measured) [online] http://www.beautycheck.de/ (accessed 12 August 2016).

Buffardi, L.E. and Campbell, W.K. (2008) 'Narcissism and social networking web sites', Personality and Social Psychology Bulletin, Vol. 34, No. 10, pp.1303-1314. 
Carr, C., Vitak, J. and McLaughlin, C. (2013) 'Strength of social cues in online impression formation: expanding the SIDE model', Communication Research, Vol. 40, No. 2, pp.261-281.

Cash, T.F., Gillen, B. and Burns, D.S. (1977) 'Sexism and 'beautyism' in personnel consultant decision making', Journal of Applied Psychology, Vol. 62, No. 3, pp.301-310.

Chan, T.K., Cheung, C.M., Shi, N. and Lee, M.K. (2015) 'Gender differences in satisfaction with Facebook users', Industrial Management \& Data Systems, Vol. 115, No. 1, pp.182-206.

Facebook (2014) Our Mission [online] http://newsroom.fb.com/company-info/ (accessed 12 March 2016).

Hall, J.A., Pennington, N. and Lueders, A. (2014) 'Impression management and formation on Facebook: a lens model approach', New Media \& Society, Vol. 16, No. 6, pp.958-982.

Hart, A.J. and Morry, M.M. (1997) 'Trait inferences based on racial and behavioral cues', Basic and Applied Social Psychology, Vol. 19, No. 1, pp.33-48.

King, A.R. and Pate, A.N. (2002) 'Individual differences in judgmental tendencies derived from first impressions', Personality and Individual Differences, Vol. 33, No. 1, pp.131-145.

Little, A.C. and Mannion, H. (2005) 'Viewing attractive and unattractive same-sex individuals changes self-rated attractiveness and face preferences in women', Animal Behavior, Vol. 72, No. 5, pp.981-87.

Lydon, J.E., Jamieson, D.W. and Zanna, M.P. (1988) 'Interpersonal similarity and the social and intellectual dimensions or first impressions', Social Cognition, Vol. 6, No. 4, pp.269-286.

Muscanell, N.L. and Guadagno, R.E. (2012) 'Make new friends or keep the old: gender and personality differences in social networking use', Computers in Human Behavior, Vol. 28, No. 1, pp.107-112.

Scott, G.G. (2014) 'More than friends: popularity on Facebook and its role in impression formation', Journal of Computer-Mediated Communication, Vol. 19, No. 3, pp.358-372.

Takeuchi, S.A. (2006) 'On the matching phenomenon in courtship: a probability matching theory of mate selection', Marriage \& Family Review, Vol. 40, No. 1, pp.25-51.

Taylor, L.S., Fiore, A.T., Mendelsohn, G.A. and Cheshire, C. (2011) 'Out of my league': a real-world test of the matching hypothesis', Personality and Social Psychology Bulletin, Vol. 37, No. 7, pp.942-954.

Temple, L.E. and Loewen, K.R. (1993) 'Perceptions of power: first impressions of a woman wearing a jacket', Perceptual and Motor Skills, Vol. 76, No. 1, pp.339-348.

Walster, E., Aronson, V., Abrahams, D. and Rottman, L. (1966) 'Importance of physical attractiveness in dating behavior', Journal of Personality and Social Psychology, Vol. 4, No. 5, pp.508-516.

Walther, J.B., Slovacek, C.L. and Tidwell, L.C. (2001) 'Is a picture worth a thousand words? Photographic images in long-term and short-term computer-mediated communication', Communication Research, Vol. 28, No. 1, pp.105-134.

Wang, S.S., Moon, S., Kwon, K.H., Evans, C.A. and Stefanone, M.A. (2010) 'Face off: implications of visual cues on initiation friendship on Facebook', Computers in Human Behavior, Vol. 26, No. 2, pp.226-234.

Weibel, D., Stricker, D., Wissmath, B. and Mast, F.W. (2010) 'How socially relevant visual characteristics of avatars influence impression formation', Journal of Media Psychology, Vol. 22, No. 1, pp.36-42.

Weibel, D., Wissmath, B. and Groner, R. (2008) 'How gender and age affect newscasters' credibility', Journal of Broadcasting and Electronic Media, Vol. 52, No. 3, pp.466-484.

Weiser, E.B. (2000) 'Gender differences in internet use patterns and internet application preferences: a two-sample comparison', CyberPsychology and Behavior, Vol. 3, No. 2, pp.167-178.

White, G.L. (1980) 'Physical attractiveness and courtship progress', Journal of Personality and Social Psychology, Vol. 39, No. 4, pp.660-668.

Wilson, R.E., Gosling, S.D. and Graham, L.T. (2012) 'A review of Facebook research in the social sciences’, Perspectives on Psychological Science, Vol. 7, No. 3, pp.203-220. 